Marquette University

e-Publications@Marquette

Chemistry Faculty Research and Publications

Chemistry, Department of

$11-1-2008$

\title{
Analyzing the Catalytic Mechanism of the Fe-Type Nitrile Hydratase from Comamonas testosteroni Ni1
}

Saroja Rao

Loyola University Chicago

Richard C. Holz

Marquette University, richard.holz@marquette.edu

Accepted version. Biochemistry, Vol. 47, No. 46 (November 2008): 12057-12064. DOI. (C) 2008 American Chemical Society. Used with permission.

Richard C. Holz was affiliated with Loyola University at the time of publication. 
Marquette University

e-Publications@Marquette

\section{Chemistry Faculty Research and Publications/College of Arts and Sciences}

This paper is NOT THE PUBLISHED VERSION; but the author's final, peer-reviewed manuscript. The published version may be accessed by following the link in the citation below.

Biochemistry, Vol. 47, No. 46 (2008): 12057-12064. DOI. This article is @ American Chemical Society and permission has been granted for this version to appear in e-Publications@Marquette. American Chemical Society does not grant permission for this article to be further copied/distributed or hosted elsewhere without the express permission from American Chemical Society.

\section{Analyzing the Catalytic Mechanism of the Fe- Type Nitrile Hydratase from Comamonas testosteroni Ni1}

Saroja Rao

Department of Chemistry, Loyola University-Chicago, 1068 West Sheridan Road, Chicago, Illinois 60626

Richard C. Holz

Department of Chemistry, Marquette University, Milwaukee, Wisconsin 53233

Department of Chemistry, Loyola University-Chicago, 1068 West Sheridan Road, Chicago, Illinois 60626

This work was supported by the National Science Foundation (CHE-0652981 to R.C.H.) 


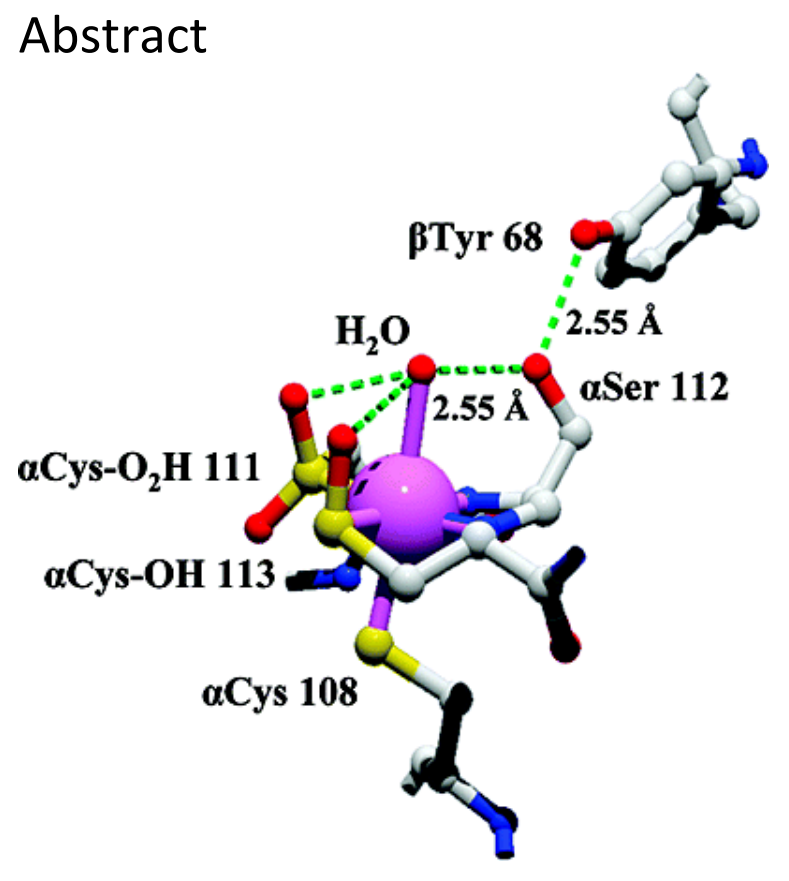

In order to gain insight into the catalytic mechanism of Fe-type nitrile hydratases (NHase), the $\mathrm{pH}$ and temperature dependence of the kinetic parameters $k_{\mathrm{cat}}, K_{\mathrm{m}}$, and $k_{\mathrm{cat}} / K_{\mathrm{m}}$ along with the solvent isotope effect were examined for the Fe-type NHase from Comamonas testosteroni Ni1 (CtNHase). CtNHase was found to exhibit a bell-shaped curve for plots of relative activity vs $\mathrm{pH}$ over $\mathrm{pH}$ values 4-10 for the hydration of acrylonitrile and was found to display maximal activity at $\mathrm{pH} \sim 7.2$. Fits of these data provided a $\mathrm{p} K_{\mathrm{ES} 1}$ value of $6.1 \pm 0.1$, a $\mathrm{p} K_{\mathrm{ES} 2}$ value of $9.1 \pm 0.2\left(k_{\mathrm{cat}}^{\prime}=10.1 \pm 0.3 \mathrm{~s}^{-1}\right)$, a $\mathrm{p} K_{\mathrm{E} 1}$ value of $6.2 \pm 0.1$, and a $\mathrm{p} K_{\mathrm{E} 2}$ value of $9.2 \pm 0.1$ $\left(k_{\text {cat }}^{\prime} / K_{m}^{\prime}\right.$ of $\left.2.0 \pm 0.2 \mathrm{~s}^{-1} \mathrm{mM}^{-1}\right)$. Proton inventory studies indicate that two protons are transferred in the ratelimiting step of the reaction at $\mathrm{pH}$ 7.2. Since $\mathrm{CtNHase}$ is stable to $25^{\circ} \mathrm{C}$, an Arrhenius plot was constructed by plotting $\ln \left(k_{\text {cat }}\right)$ vs $1 / T$, providing an $E_{\mathrm{a}}$ of $33.3 \pm 1.5 \mathrm{~kJ} / \mathrm{mol}$. $\Delta H^{\circ}$ of ionization values were also determined, thus helping to identify the ionizing groups exhibiting the $\mathrm{p} K_{\mathrm{ES} 1}$ and $\mathrm{p} K_{\mathrm{ES} 2}$ values. Based on $\Delta H^{\circ}$ ion data, $\mathrm{p} K_{\mathrm{ES} 1}$ is assigned to $\beta$ Tyr68 while $p K_{\mathrm{ES} 2}$ is assigned to $\beta$ Arg52, $\beta$ Arg157, or $\alpha$ Ser116 (NHases are $\alpha_{2} \beta_{2}$ heterotetramers). Given the strong similarities in the kinetic data obtained for both Co- and Fe-type NHase enzymes, both types of NHase enzymes likely hydrate nitriles in a similar fashion.

\section{Introduction}

Nitrile hydratase (NHase, EC 4.2.1.84) catalyzes the hydration of nitriles to their corresponding higher value amides at ambient pressures and temperatures at physiological pH (Scheme 1 ) $(1,3-9)$. Microbial NHases have great potential as catalysts for organic chemical processing because these enzymes can convert nitriles to the corresponding higher value amides in a chemo-, regio-, and/or enantioselective manner (8). At this time, Mitsubishi Rayon Co. has developed a microbial process that produces 30000 tons of acrylamide annually, using the NHase from Rhodococcus rhodochrous $\mathrm{J1}(5,10-12)$. This process constitutes the first successful example of a bioconversion process for the manufacture of a commodity chemical. Several other processes for the production of interesting pharmaceutical intermediates and building blocks such as $(S)$-pipecolic acid, $(S)$ piperidine-2-carboxylic acid, (S)-2,2-dimethylcyclopropane carboxamide, and (S)-3,3,3-trifluoro-2-hydroxy-2methylpropionic acid have been developed using nitrile-hydrolyzing bacteria and enzymes (13). One of the most attractive features of nitrile-metabolizing enzymes is their ability to selectively hydrolyze one cyano group of a dinitrile to its corresponding amide, something that is virtually impossible using conventional chemical methods (14-18). Therefore, the potential of nitrile-hydrolyzing enzymes for the production of several fine chemicals is being increasingly recognized. 


\section{Scheme 1}

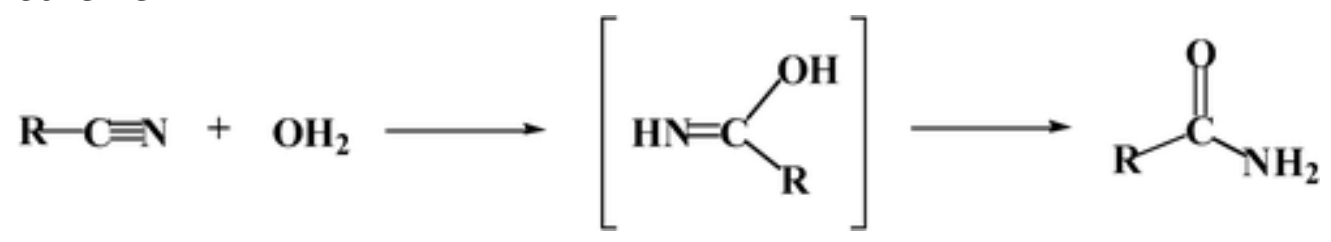

NHases are metalloenzymes that contain either a non-heme Fe(III) ion ("Fe-type") or a non-corrin Co(III) ion ("Co-type") in their active site $(7,8,12,19)$. Both Fe-type and Co-type NHases have been crystallographically characterized, and in all structures reported to date, the trivalent metal ions are six coordinate with the ligand sphere made up of three cysteines, two amide nitrogens, and a water/hydroxide molecule $(1,20-22)$. Interestingly, two of the active site cysteine residues are posttranslationally modified to cysteinesulfinic acid $\left(-\mathrm{SO}_{2} \mathrm{H}\right)$ and cysteinesulfenic acid $(-\mathrm{SOH})$ yielding an unusual metal coordination geometry, which was termed a "claw setting". However, a recent high-resolution X-ray crystal structure (1.3 $\AA$ ) of the Fe-type NHase from Rhodococcus erythropolis AJ270 revealed that both equatorial cysteine residues are oxidized to sulfinic acids (23). Thus, it is unclear whether both Co-type and Fe-type NHase enzymes contain two sulfinic acid ligands or one sulfinic and one sulfenic acid ligand. Based on theoretical calculations, the carbon-nitrogen bond in the coordinated amide of both Fe-type and Co-type NHases has significant double bond character, suggesting they are best represented as imido-metal bonds (24).

Crystallographic characterization of both Fe-type and Co-type NHase enzymes, along with several elegant studies on NHase biomimetic complexes $(7,19,25)$, has provided insight into how the molecular structure controls enzyme function. Even so, details of the enzymatic reaction remain elusive. Recently, the first detailed catalytic mechanism for an NHase was proposed (26). This mechanism suggested that three active site residues, $\beta T r p 72, \beta T y r 68$, and $\alpha$ Ser112, in the active site of the Co-type NHase from Pseudonocardia thermophila JCM 3095 (PtNHase) 1 form a catalytic triad (Figure 1) (26). However, based on sequence alignment between PtNHase and the Fe-type NHase from Comamonas testosteroni Ni1 (CtNHase), the residue corresponding to $\beta \operatorname{Trp} 72$ in PtNHase is a valine in CtNHase (Figure 2). In order to gain insight into the catalytic mechanism of Fe-type NHase enzymes and determine the catalytic role of $\beta$ Trp72 in PtNHase, we have examined the $\mathrm{pH}$ and temperature dependence of the kinetic parameters, along with the solvent isotope effect of CtNHase. Based on these data, new insights into the catalytic mechanism of both Co-type and Fe-type NHase enzymes are gleaned. 
Figure 1

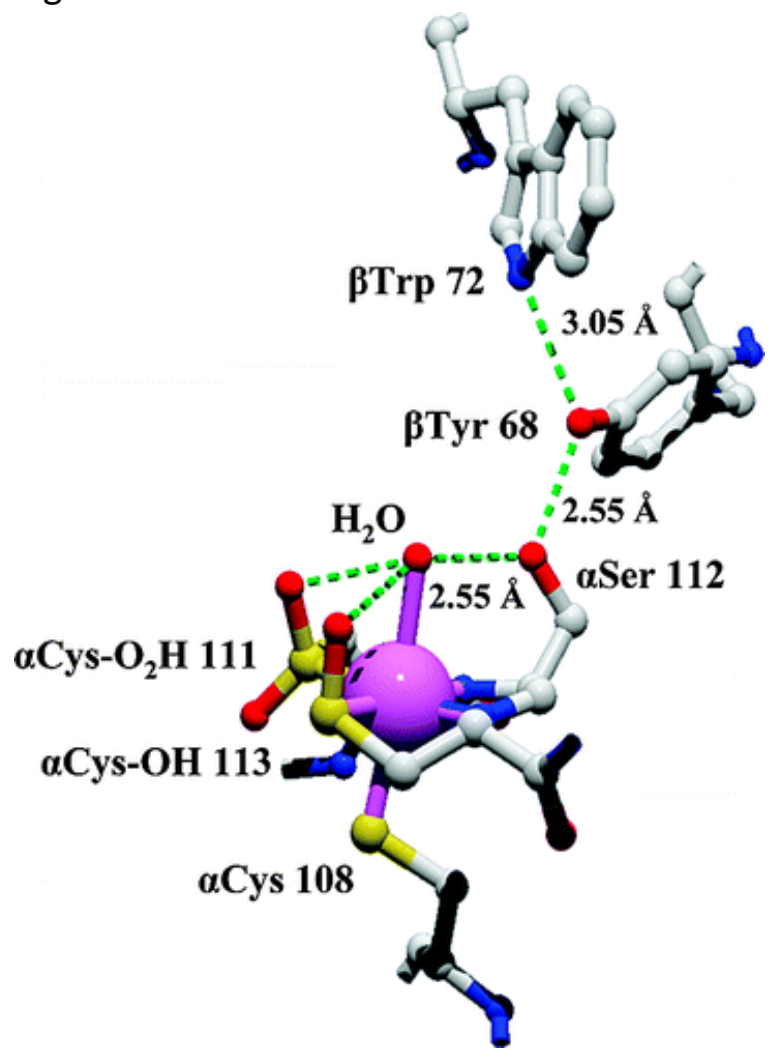

Figure 1. Active site of PtNHase (1IRE) (1). Trivalent cobalt ion is six coordinate with three cysteine sulfurs, two amide nitrogens, and a water molecule. $\beta$ Trp72, which forms a hydrogen bond with $\beta$ Tyr68, is replaced with a valine in CtNHase.

\section{Figure 2}

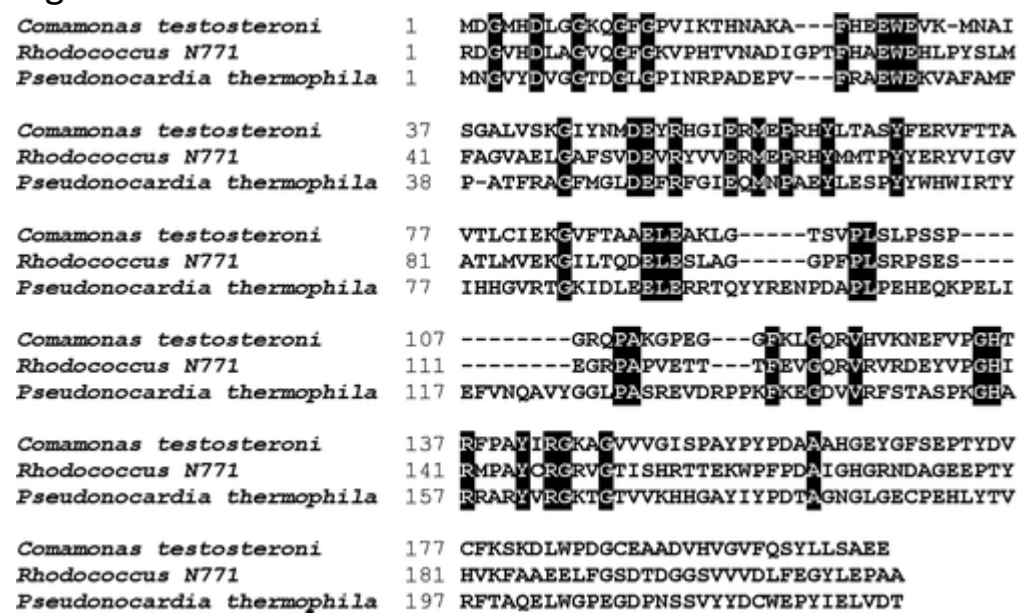

Figure 2. Sequence alignment of the $\beta$-subunits of the NHase from C. testosterone and the crystallographically characterized NHase enzymes from Rhodococcus N771 and $P$. thermophila. 


\section{Materials and Methods}

\section{Expression and Purification of Recombinant CtNHase}

All chemicals used in this study were purchased from commercial sources and were of the highest quality available. The plasmids encoding the $\alpha$ - and $\beta$-subunits of $C t N H$ ase and subunits of the $E$. coli chaperones GroES

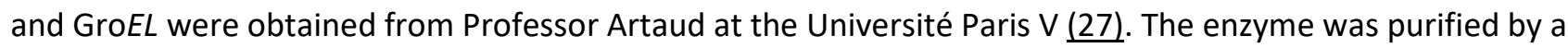
simplified procedure based on the previously published purification method for PtNHase $(5,26,27)$. Briefly Escherichia coli BL-21 Star (DE3) cells were cotransformed with the pXL2205 and pGroES/EL plasmids, which contain the genes for the $\alpha$ - and $\beta$-subunits and an activator proteins, by electroporation. The cells were incubated in $1 \mathrm{~mL}$ of Luria-Bertani (LB) medium for $1-2 \mathrm{~h}$ in the absence of antibiotics at $37^{\circ} \mathrm{C}$ and then transferred to $100 \mathrm{~mL}$ of the same medium supplemented with ampicillin and chloramphenicol $(50 \mu \mathrm{g} / \mathrm{mL}$ of each) and incubated overnight at $37^{\circ} \mathrm{C}$. This inoculum was used to inoculate $5 \mathrm{~L}$ of LB broth containing ampicillin and chloramphenicol ( $50 \mathrm{\mu g} / \mathrm{mL}$ of each) which was placed in five $2 \mathrm{~L}$ shake flasks at $28^{\circ} \mathrm{C}$, shaking at $180 \mathrm{rpm}$. The cells were cultured for an additional $6 \mathrm{~h}$ at $28^{\circ} \mathrm{C}$ and $180 \mathrm{rpm}$. The cells were harvested by centrifugation (5000 $\mathrm{g}, 10 \mathrm{~min}$ at $4{ }^{\circ} \mathrm{C}$ ) and resuspended in buffer $\mathrm{A}$ ( $100 \mathrm{mM}$ HEPES, pH 7.2, $40 \mathrm{mM}$ butyric acid) on ice. The cells were lysed on ice by sonication in the presence of the protease inhibitors phenylmethanesulfonyl fluoride, leuptin, pepstatin, and aprotinin $(10 \mu \mathrm{g} / \mathrm{mL}$ of each). The cell debris was removed by centrifugation at $13000 \mathrm{~g}$ for $15 \mathrm{~min}$, and the supernatant was stored at $-20^{\circ} \mathrm{C}$ until further use.

The cell lysate was applied to a Q-Sepharose column (Hi trap QFF, $5 \mathrm{~mL}$; GE Healthcare) under the control of an ÄKTA prime plus system (GE Health Care). The column was equilibrated with buffer $A$, and the same buffer was used to wash the column until no protein was detected in the flow-through. A $40 \mathrm{~mL}$ salt gradient was run from 0 to $0.8 \mathrm{M} \mathrm{KCl}$. The active fractions were eluted at $0.3 \mathrm{M} \mathrm{KCl}$ and concentrated using an Amicon ultrafiltration system. The concentrated fraction was brought to $20 \%$ saturation with ammonium sulfate and applied to a phenyl-Sepharose column (Hi trap phenyl FF, $5 \mathrm{~mL}$; GE Healthcare). The enzyme was eluted using a gradient of $20-0 \%$ ammonium sulfate. Active enzyme fractions were eluted at $\sim 6 \%$ ammonium sulfate. The active fractions were pooled, concentrated, and desalted using a Centricon Plus-20 device (Millipore). The concentrated fraction was loaded onto a Sephacryl S300 column $(1.6 \mathrm{~cm} \times 60 \mathrm{~cm})$, which had been preequilibrated with buffer $A$, and eluted at a flow rate of $0.5 \mathrm{~mL} / \mathrm{min}$. Active fractions were pooled and applied to a Mono $\mathrm{Q}$ column ( $1 \mathrm{~mL} ; \mathrm{GE}$ Healthcare) that had been previously equilibrated with buffer A. Elution of the enzyme was achieved with a 20 $\mathrm{mL}$ gradient of $0-0.5 \mathrm{M} \mathrm{NaCl}$. A single peak containing the pure fraction was eluted between 0.2 and $0.3 \mathrm{M} \mathrm{NaCl}$, which was concentrated and desalted using a Centricon Plus-20 device. This sample was stored in the presence of $40 \mathrm{mM}$ butyric acid at $-80^{\circ} \mathrm{C}$ until further use.

\section{Kinetic Assay}

During the purification process, the enzyme was assayed for catalytic activity using acrylonitrile as the substrate in $100 \mathrm{mM}$ HEPES buffer, $\mathrm{pH} 7.2$ at $20^{\circ} \mathrm{C}(10)$. In this assay the hydration of acrylonitrile $(20 \mathrm{mM})$ was measured spectrophotometrically by monitoring the formation of acrylamide at $235 \mathrm{~nm}\left(\varepsilon=1106 \mathrm{~mol}^{-1} \mathrm{~cm}^{-1}\right)(10)$. All assays were performed on a Shimadzu UV-2450 PC spectrophotometer equipped with a constant-temperature cell holder and an ISOTEMP 2013 D water bath (Fisher Scientific, Pittsburgh, PA). Enzyme concentrations were determined using a Bradford assay with bovine serum albumin as the standard (28). All assays were performed at $20 \pm 0.1^{\circ} \mathrm{C}$ in $100 \mathrm{mM}$ HEPES buffer at pH 7.2.

\section{$\mathrm{pH}$ Profiles}

The enzymatic activities of $\mathrm{CtNH}$ ase at $\mathrm{pH}$ values between 4.0 and 10.0 were measured using acrylonitrile as the substrate. The concentration of each buffer used was $20 \mathrm{mM}$, and the following buffers were used: sodium tetraborate $(\mathrm{pH} 9.20-10.00)$, borate $(\mathrm{pH} 8.00-9.20)$, HEPES ( $\mathrm{pH} 6.80-8.00)$, MES (pH 5.50-6.80), and acetate $(\mathrm{pH}$ 4.00-5.50). The kinetic parameters $k_{\mathrm{cat}}, K_{\mathrm{m}}$, and $k_{\mathrm{cat}} / K_{\mathrm{m}}$ were determined using seven to eight different substrate concentrations ranging from 0.2 to 10 times the observed $K_{\mathrm{m}}$ value at each $\mathrm{pH}$ studied. When transitioning 
between buffers, experiments were run at identical $\mathrm{pH}$ values but in different buffers with no observed effect on the kinetic parameters. Kinetic parameters and fits to the kinetic curves were obtained using IGOR Pro

(Wavemetrix Inc., Lake Oswego, OR).

\section{Solvent Isotope Effect Profiles}

All buffers were prepared from a freshly opened bottle of $99.9 \%\left({ }^{2} \mathrm{H}\right) \mathrm{H}_{2} \mathrm{O}$ (Aldrich). The buffers used in the preparation of all deuterated buffers were in the anhydrous form. The $\mathrm{pH}$ of each buffer used was adjusted by the addition of $\mathrm{NaOD}$ or $\mathrm{DCl}$ (both $99 \%+$ deuterium content; Acros Organics, Geel, Belgium) and corrected for deuteration by adding 0.4 to the reading of the $\mathrm{pH}$ electrode $\underline{(29)}$.

\section{Results}

\section{$\mathrm{pH}$ Profiles of the Kinetic Parameters}

The kinetic parameters $K_{\mathrm{m}}, k_{\text {cat }}$, and $k_{\text {cat }} / K_{\mathrm{m}}$ were determined as a function of $\mathrm{pH}$ for CtNHase using acrylonitrile as the substrate. At pH 7.2 and $20^{\circ} \mathrm{C}$, a $k_{\text {cat }}$ value of $10.0 \pm 0.2 \mathrm{~s}^{-1}$, a $K_{\mathrm{m}}$ value of $5.0 \pm 1.3 \mathrm{mM}$, and a $k_{\text {cat }} / K_{\mathrm{m}}$ value of $2.0 \pm 0.2 \mathrm{~s}^{-1} \mathrm{mM}^{-1}$ were obtained for CtNHase in the absence of $n$-butyric acid (30). These values are similar to those reported for the Fe-type NHase from the thermophilic Bacillus strain DSM 2349 (31). CtNHase was found to exhibit a bell-shaped curve for plots of relative activity vs $\mathrm{pH}$ over $\mathrm{pH}$ values between 4.0 and 10 and was found to display maximal catalytic activity at $\mathrm{pH} \sim 7.2$. Plots of $\log \left(k_{\text {cat }}\right)$ and $\log \left(k_{\text {cat }} / K_{\mathrm{m}}\right)$ vs $\mathrm{pH}$ were prepared for CtNHase and fit to eqs 1 and 2, respectively (Figure $\underline{3}$ ) (32):

$$
\begin{aligned}
\log \left(k_{\text {cat }}\right) & =\log \left[k^{\prime}{ }_{\text {cat }} /\left(1+[\mathrm{H}] / K_{\mathrm{ES} 1}+K_{\mathrm{ES} 2} /[\mathrm{H}]\right)\right] \\
\log \left(k_{\text {cat }} / K_{\mathrm{m}}\right) & =\log \left[{k^{\prime}}_{\text {cat }} / K^{\prime}{ }_{\mathrm{m}} /\left(1+[\mathrm{H}] / K_{\mathrm{ES} 1}+K_{\mathrm{ES} 2} /[\mathrm{H}]\right)\right]
\end{aligned}
$$

where $k_{\text {cat }}^{\prime}$ is the theoretical maximal velocity, $k_{\text {cat }}^{\prime} / K_{m}^{\prime}$ is the theoretical maximal catalytic efficiency, $K_{\mathrm{ES} 1}$ is the ionization constant of the ES complex which affects the acidic side of the $\mathrm{pH}$ curve, $K_{\mathrm{ES} 2}$ reflects the basic side, and $K_{\mathrm{E} 1}$ and $K_{\mathrm{E} 2}$ are ionization constants for an acidic group and basic group, respectively, on the free enzyme or free substrate (Scheme $\underline{2}$ ). Inspection of a plot of $\log \left(K_{\mathrm{m}}\right) \mathrm{vs} \mathrm{pH}$ (Figure $\underline{3}$ ) indicated that $K_{\mathrm{m}}$ does not vary with $\mathrm{pH}$. Therefore, plots of $\log \left(k_{\mathrm{cat}}\right)$ vs $\mathrm{pH}$ and plots of $\log \left(k_{\mathrm{cat}} / K_{\mathrm{m}}\right)$ vs $\mathrm{pH}$ provided similar $\mathrm{p} K_{\mathrm{a}}$ values (Table $\underline{1}$ ). 
Figure 3
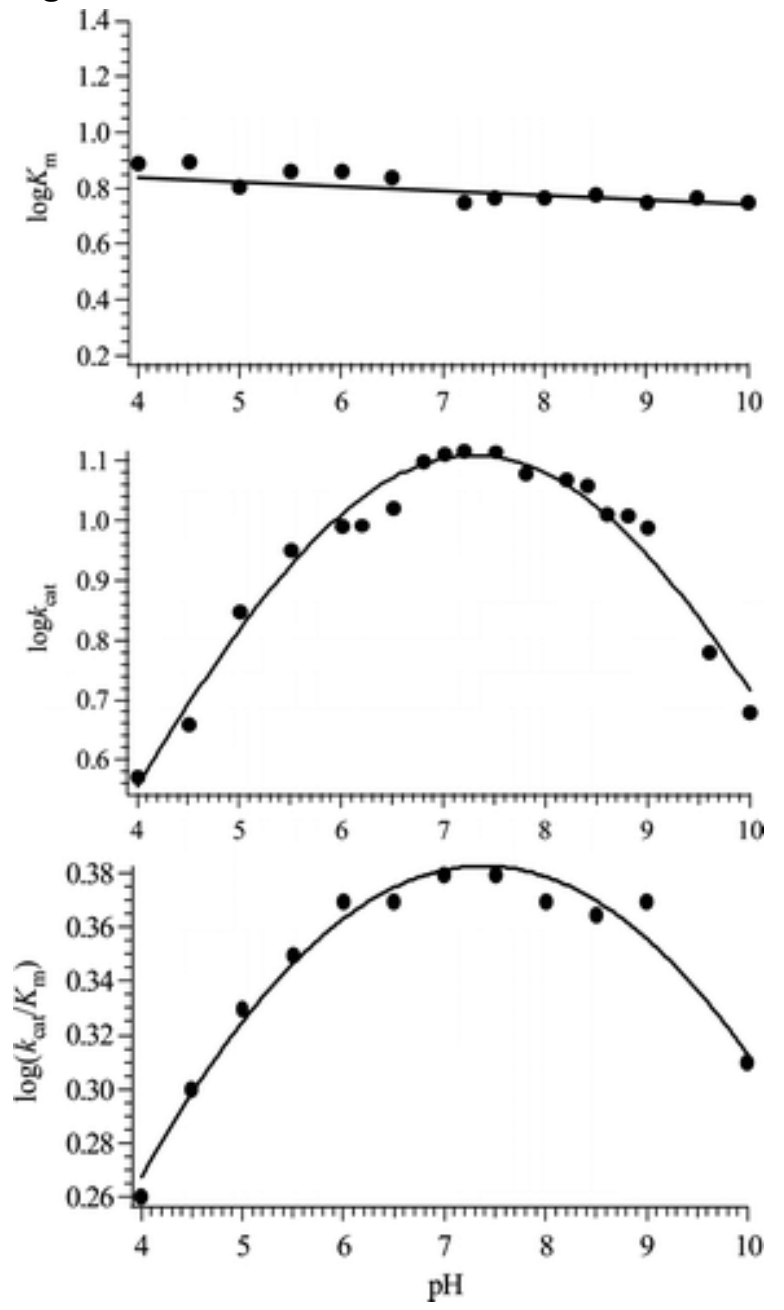

Figure 3. Effect of $\mathrm{pH}$ on the kinetic parameters for the hydration of acrylonitrile to acrylamide by CtNHase between $\mathrm{pH} 4.0$ and $\mathrm{pH} 10.0$. The $K_{\mathrm{m}}$ does not vary with $\mathrm{pH}$. The $\mathrm{pH}$ dependence of $k_{\text {cat }}$ is fit to eq $\underline{1}$, and the $\mathrm{pH}$ dependence of $K_{\text {cat }} / K_{\mathrm{m}}$ is fit to eq $\underline{2}$. The kinetic constants obtained from the fits are listed in Table $\underline{1}$.

Scheme 2

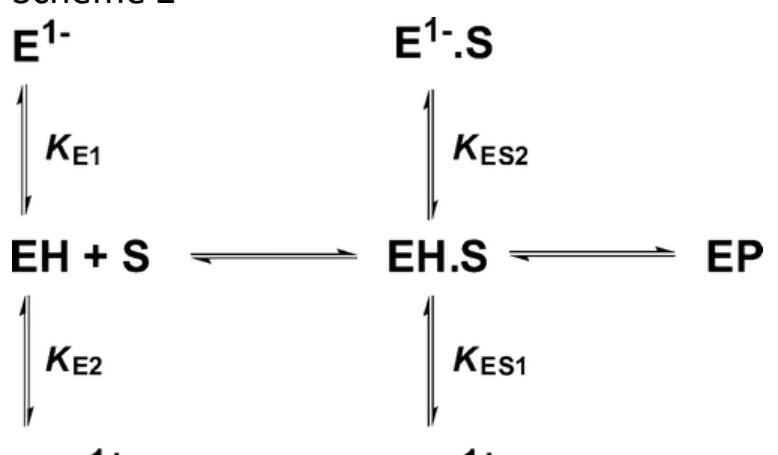

$\mathrm{EH}_{2}{ }^{1+} \quad \mathrm{EH}_{2}{ }^{1+} \cdot \mathrm{S}$

Table 1. Ionization Constants for Acrylonitrile Hydration by CtNHase

\section{CtNHase PtNHasea}

$k_{\text {cat }}$ Vs $\mathrm{pH}$ 


\begin{tabular}{|l|l|l|}
\hline $\mathrm{p} K_{\mathrm{ES} 1}$ & $6.1 \pm 0.1$ & $5.9 \pm 0.1$ \\
\hline $\mathrm{p} K_{\mathrm{ES} 2}$ & $9.1 \pm 0.2$ & $9.2 \pm 0.1$ \\
\hline$k_{\mathrm{cat}}^{\prime}\left(\mathrm{s}^{-1}\right)$ & $10.1 \pm 0.3$ & $130 \pm 1$ \\
\hline \multicolumn{1}{|c|}{$k_{\mathrm{cat}} / K_{\mathrm{m}} \mathrm{vs} \mathrm{pH}$} & & \\
\hline $\mathrm{p} K_{\mathrm{E} 1}$ & $6.2 \pm 0.1$ & $5.8 \pm 0.1$ \\
\hline $\mathrm{p} K_{\mathrm{E} 2}$ & $9.2 \pm 0.1$ & $9.1 \pm 0.1$ \\
\hline$k^{\prime}{ }_{\mathrm{cat}} / K_{\mathrm{m}}^{\prime}\left(\mathrm{s}^{-1} \mathrm{mM}^{-1}\right)$ & $2.0 \pm 0.2$ & $6.5 \pm 0.1 \times 10^{3}$ \\
\hline
\end{tabular}

${ }^{\mathrm{a}}$ Data taken from ref $\underline{26}$.

A plot of $\log \left(k_{\text {cat }}\right)$ vs $\mathrm{pH}$ provided a bell-shaped curve that was fit to eq $\underline{1}$ (Figure $\underline{3}$ ). The magnitude of the slopes calculated as prescribed (33) for the acidic and basic limbs are unity, indicating that one group is ionized on each limb. Fits to eq 1 provided a $\mathrm{p} K_{\mathrm{ES} 1}$ value of $6.1 \pm 0.1$, a $\mathrm{p} K_{\mathrm{ES} 2}$ value of $9.1 \pm 0.2$, and a $k_{\text {cat }}^{\prime}$ value of $10.1 \pm 1.2 \mathrm{~s}^{-1}$. Similarly, plots of $\log \left(k_{\mathrm{cat}} / K_{\mathrm{m}}\right)$ vs $\mathrm{pH}$ were fit to eq 2 , providing a $\mathrm{p} K_{\mathrm{E} 1}$ value of $6.2 \pm 0.2$, a $\mathrm{p} K_{\mathrm{E} 2}$ value of $9.2 \pm 0.1$, and a $k_{\text {cat }}^{\prime} / K_{m}^{\prime}$ value of $2.0 \pm 0.2 \mathrm{~s}^{-1} \mathrm{mM}^{-1}$ (Figure $\underline{3}$ ).

\section{Solvent Isotope Effect Studies}

Solvent isotope effect studies were carried out on CtNHase using acrylonitrile as the substrate at pH 7.2 by substituting hydrogen $\left({ }^{1} \mathrm{H}\right)$ with deuterium $\left({ }^{2} \mathrm{H}\right) . k_{\text {cat }}$ values for acrylonitrile were measured, in the absence of butyric acid, at several different ratios of $\mathrm{D}_{2} \mathrm{O}$ and $\mathrm{H}_{2} \mathrm{O}$, and the results were plotted as atom fraction of deuterium vs $V_{n} / V_{0}$, where $V_{n}$ is the observed velocity at $n$ fraction of deuterium, whereas $V_{0}$ is the observed velocity in water (Figure 4). Proton inventories and fractionation factors were obtained by fitting the experimental data to equations derived from the Gross-Butler equation $\underline{(34,35)}$, as previously described $\underline{26}$, 36). At pH 7.2 the data deviate from linearity, and the best fit was obtained for a polynomial, suggesting at least two protons are transferred in the transition state at this $\mathrm{pH}$ (Figure $\underline{4}$ ).

Figure 4

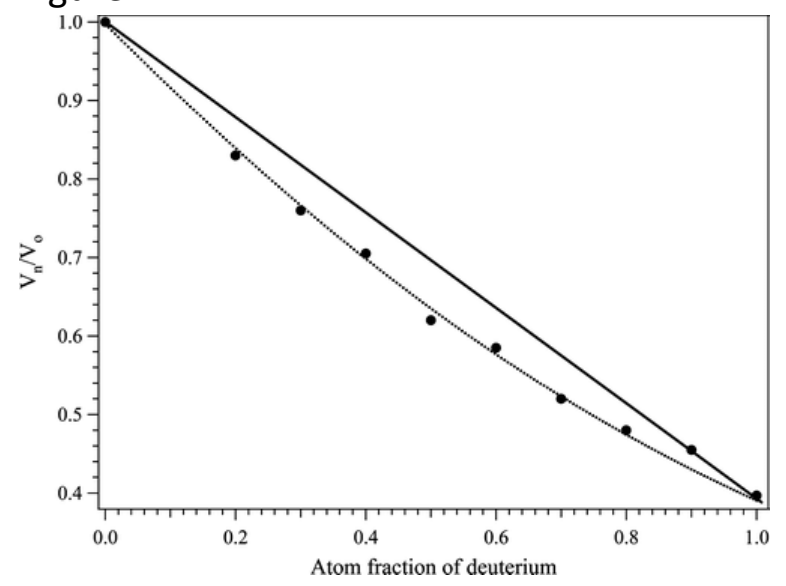

Figure 4. Plot of $V_{n} / V_{0}$ vs atom fraction of deuterium for $C t$ NHase at $\mathrm{pH}$ 7.2. $V_{n} / V_{0}$ is defined as velocity at $n$ atom fraction of deuterium over velocity in water. The solid line represents a linear relationship; the dashed line is a fit to Elrods equation (2) indicating two protons are transferred in the transition state with fractionation factors $\varphi_{\mathrm{T} 1}=0.62$ and $\varphi_{\mathrm{T} 2}=0.64$.

Since the largest deviation for theoretical proton inventory curves occurs at atom fractions of $0.5 \underline{(2,37)}$, calculation of a midpoint partial solvent isotope effect often helps in determining the number of protons involved in the catalytic reaction. The following equations, derived by Elrod (2), allowed the calculation of midpoint partial solvent isotope effects when the experimental data were obtained at different atom fractions: 


$$
\begin{aligned}
& \text { one proton: } V_{\mathrm{m}} / V_{1}=\left(1-n_{\mathrm{m}}\right)\left(V_{0} / V_{1}\right)+n_{\mathrm{m}} \\
& \text { two proton: } V_{\mathrm{m}} / V_{1}=\left[\left(1-n_{\mathrm{m}}\right)\left(V_{0} / V_{1}\right)^{1 / 2}+n_{\mathrm{m}}\right]^{2} \\
& \text { general solvation: } V_{\mathrm{m}} / V_{1}=\left(V_{0} / V_{1}\right)^{1-n_{\mathrm{m}}}
\end{aligned}
$$

where $n_{m}=0.49$ (the $\mathrm{H}_{2} \mathrm{O} / \mathrm{D}_{2} \mathrm{O}$ ratio at the midpoint), $V_{m} / V_{1}$ equals the midpoint partial solvent isotope effect, $V_{0} / V_{1}$ represents the total isotope effect (velocity in $100 \% \mathrm{H}_{2} \mathrm{O} /$ velocity in $100 \% \mathrm{D}_{2} \mathrm{O}$ ). The experimental and calculated midpoint partial isotope effects are presented in Table 2. The presence of $\mathrm{D}_{2} \mathrm{O}$ lowered the catalytic activity of $\mathrm{CtNHase}$ resulting in a solvent isotope effect of 2.55 (Figure 4 ). A plot of atom fraction of deuterium vs $V_{n} / V_{1}$ (velocity at $n$ fraction of deuterium/velocity in $100 \% D_{2} \mathrm{O}$ ) obtained for the reaction of acrylonitrile by CtNHase was best fit to eq $\underline{4}$, indicating two protons are transferred during the rate-limiting step at $\mathrm{pH}$ 7.2. However, midpoint partial isotope effect calculations do not strongly distinguish between two protons transferred and generalized solvent effects (Table 2). Since $K_{\mathrm{m}}$ was found to be independent of pH over the entire $\mathrm{pH}$ range studied, $k_{\text {cat }} / K_{\mathrm{m}}$ for $P t$ NHase in deuterium is 1.34 .

Table 2. Comparison of Experimental Midpoint Solvent Isotope Effects with Calculated Midpoint Solvent Isotope Effectsa

\begin{tabular}{|l|l|l|l|l|l|}
\hline enzyme & $\boldsymbol{V}_{\mathbf{0}} / \mathbf{V}_{\mathbf{1}}$ & $\begin{array}{c}\text { calcd midpoint solvent } \\
\text { isotope effect }\end{array}$ & & \\
isotope effect $\boldsymbol{V}_{\mathbf{m}} / \boldsymbol{V}_{\mathbf{1}}$ & & one proton & $\begin{array}{c}\text { two } \\
\text { protons }\end{array}$ & $\begin{array}{c}\text { generalized solvation } \\
\text { changes }\end{array}$ \\
\hline CtNHase & 2.55 & 1.63 & 1.75 & 1.66 & 1.59 \\
\hline PtNHase $\underline{b}$ & 2.07 & 1.45 & 1.53 & 1.45 & 1.43 \\
\hline
\end{tabular}

${ }^{a}$ The experiment was carried out using acrylonitrile as the substrate at $\mathrm{pH}$ 7.2. Experimental and theoretical midpoint isotope effects were calculated for 0.49 atom fraction of deuterium.

${ }^{\mathrm{b}}$ Data taken from ref $\underline{26}$.

\section{Temperature Dependence of $K_{\mathrm{m}}$ and $k_{\mathrm{cat}}$}

CtNHase is stable up to $25^{\circ} \mathrm{C}$ for several minutes; therefore, the hydration rate of acrylonitrile was measured in triplicate between 4 and $25^{\circ} \mathrm{C}$ at six to eight substrate concentrations ranging from 0.5 to $20 \mathrm{mM}$. From these data, both $K_{\mathrm{m}}$ and $k_{\text {cat }}$ values were derived by fitting the experimental data to the Michaelis-Menten equation at each temperature studied. Both $k_{\mathrm{cat}}$ and $K_{\mathrm{m}}$ increased with increasing temperature. An Arrhenius plot was constructed by plotting $\ln \left(k_{\text {cat }}\right)$ vs $1 / T$ (Figure $\underline{5}$ ). A linear plot was obtained, indicating that the rate-limiting step does not change as the temperature is increased (32). From the slope of the line, the activation energy, $E_{a}$, for temperatures between 277 and $298 \mathrm{~K}$ was found to be $33.3 \pm 3.5 \mathrm{~kJ} / \mathrm{mol}$ (38). Since the slope of an Arrhenius plot is equal to $-E_{\mathrm{a} 1} / R$, where $R=8.3145 \mathrm{~J} \mathrm{~K}^{-1} \mathrm{~mol}^{-1}$, other thermodynamic parameters were calculated by the following relations: $\Delta G^{\ddagger}=-R T \ln \left(k_{\mathrm{cat}} h / k_{\mathrm{B}} T\right), \Delta H^{\ddagger}=E_{\mathrm{a}}-R T$, and $\Delta S^{\ddagger}=\left(\Delta H^{\ddagger}-\Delta G^{\ddagger}\right) / T$, where $k_{\mathrm{B}}, h$, and $R$ are the Boltzmann, Planck, and gas constants, respectively (Table $\underline{3}$ ). Assuming $K_{\mathrm{d}}$ is roughly equal to $K_{\mathrm{m}}$, a linear plot was obtained for $\ln \left(1 / K_{\mathrm{m}}\right)$ vs $1 / T$ which provides $\Delta H^{\circ}$ by multiplying the negative slope by $R$. The following thermodynamic parameters were then calculated using $\Delta G^{\circ}=-R T \ln \left(1 / K_{\mathrm{m}}\right)$ and $\Delta S^{\circ}=\left(\Delta H^{\circ}-\Delta G^{\circ}\right) / T(T a b l e ~ \underline{3})$. 
Figure 5

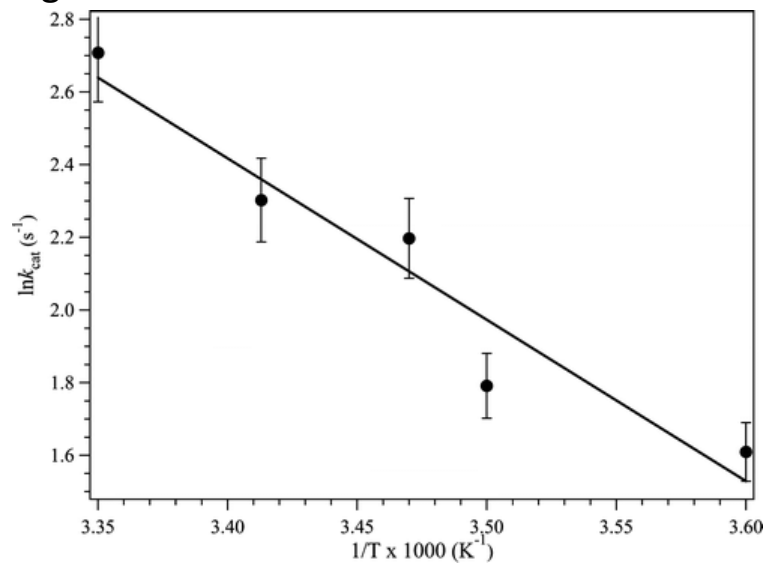

Figure 5. Arrhenius plot of acrylonitrile hydration catalyzed by $\mathrm{CtNH}$ ase at five different temperatures between 4 and $25^{\circ} \mathrm{C}$. The solid line is a linear fit to the data.

Table 3. Thermodynamic Parameters for Acrylonitrile Hydration by CtNHase at $20^{\circ} \mathrm{C}$

\begin{tabular}{|l|l|l|l|}
\hline & & \multicolumn{1}{c|}{ CtNHase } & \multicolumn{1}{c|}{ PtNHasea } \\
\hline $\mathrm{E}+\mathrm{S} \rightarrow \mathrm{ES}$ & $\Delta G^{\circ}(\mathrm{kJ} / \mathrm{mol})$ & $-9.7 \pm 0.5$ & $-7.3 \pm 0.4$ \\
\hline & $\Delta H^{\circ}(\mathrm{kJ} / \mathrm{mol})$ & $-14.3 \pm 0.5$ & $-10.2 \pm 0.5$ \\
\hline & $\Delta S^{\circ}(\mathrm{J} / \mathrm{mol})$ & $-10.3 \pm 0.7$ & $-9.7 \pm 0.7$ \\
\hline \multirow{E}{*}{$\rightarrow(\mathrm{ES} \cdot \mathrm{EP})^{\ddagger}$} & $\Delta G^{\ddagger}(\mathrm{kJ} / \mathrm{mol})$ & $63.2 \pm 0.5$ & $61.1 \pm 1.0$ \\
\hline & $\Delta H^{\mp}(\mathrm{kJ} / \mathrm{mol})$ & $30.8 \pm 0.8$ & $18.0 \pm 0.9$ \\
\hline & $\Delta S^{\ddagger}(\mathrm{J} / \mathrm{mol})$ & $-110.4 \pm 0.7$ & $-146.0 \pm 0.7$ \\
\hline & $E_{\mathrm{a}}(\mathrm{kJ} / \mathrm{mol})$ & $33.3 \pm 3.5$ & $23 \pm 1.2$ \\
\hline
\end{tabular}

${ }^{a}$ Data taken from ref $\underline{26}$.

The $\mathrm{pH}$ dependence of $k_{\mathrm{cat}}$ at saturating substrate concentrations $(20 \mathrm{mM})$ at several $\mathrm{pH}$ values between 5 and 10 was also examined at five different temperatures in order to determine the identity of the ionizing groups exhibiting the $\mathrm{p} K_{\mathrm{ES} 1}$ and $\mathrm{p} K_{\mathrm{ES} 2}$ values of 6.1 and 9.1, respectively. These data were fit to eq 1 , providing three ionization constants, one for each temperature. A plot of ionization constants vs $1 / T$ provides a slope equal to

$$
\text { slope }=\Delta H_{\text {ion }} / 2.303 R
$$

where $R$ is the gas constant (Figure $\underline{6}$ ) (39). The enthalpies of ionization calculated from these data are $7.5 \pm 0.2$ and $13.0 \pm 0.2 \mathrm{kcal} / \mathrm{mol}$. The enthalpy of ionization calculated for $\mathrm{p} K_{\mathrm{ES} 1}$ is in the range consistent with a tyrosine or histidine residue $(6.0-7.5 \mathrm{kcal} / \mathrm{mol})(32,37)$. On the other hand, the enthalpy of ionization for $\mathrm{p} K_{\mathrm{ES} 2}$ falls in the range typically observed for serine or arginine $(12-13 \mathrm{kcal} / \mathrm{mol})(32,37)$. 
Figure 6
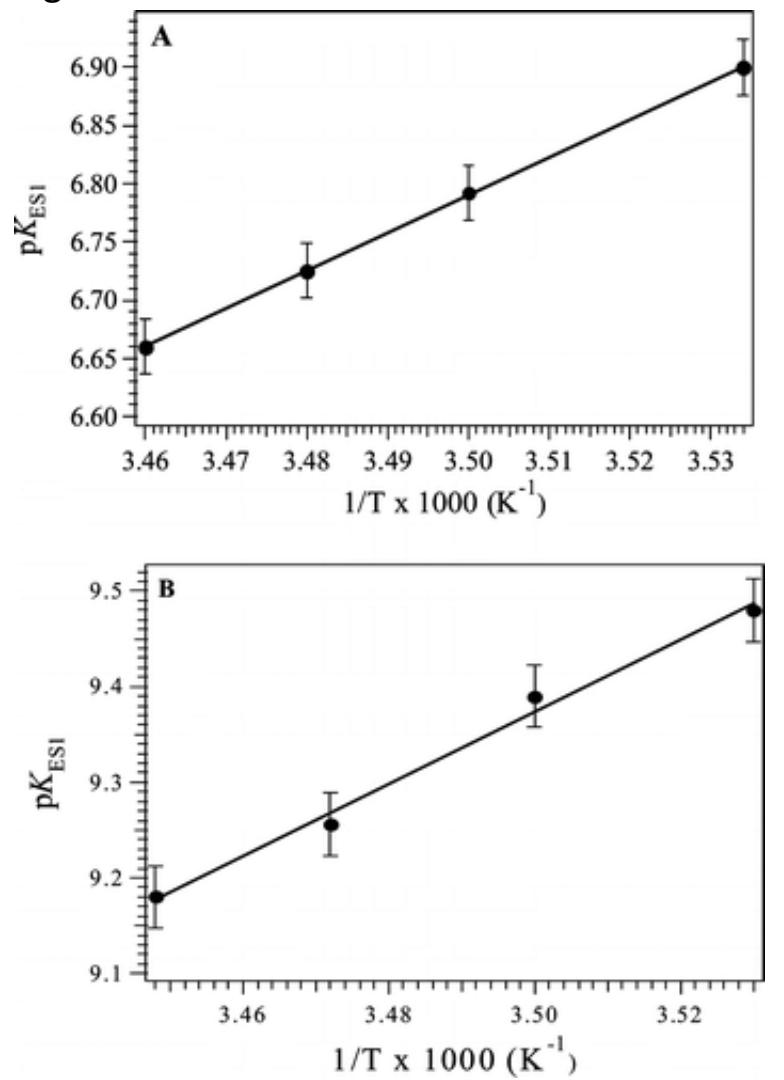

Figure 6. Plots of the ionization constants $\mathrm{p} K_{\mathrm{ES} 1}(\mathrm{~A})$ and $\mathrm{p} K_{\mathrm{ES} 2}(\mathrm{~B}) \mathrm{vs} 1 / T$ for the hydration of acrylonitrile catalyzed by $\mathrm{CtNHase.}$

\section{Discussion}

Recently, a detailed catalytic mechanism of a Co-type NHase enzyme was proposed (26) based on a combination of X-ray crystallographic, kinetic, spectroscopic, theoretical modeling, and synthetic model complex data $(7,19)$. This mechanism involved a catalytic triad formed between $\beta$ Trp72, $\beta$ Tyr68, and $\alpha$ Ser112 (PtNHase numbering) (Figure 1). It was proposed that $\beta$ Tyr68 in PtNHase is deprotonated at $\mathrm{pH} 7.6$, and this deprotonation process is represented by the $\mathrm{p} K_{\mathrm{a}}$ observed at 5.9, while $\alpha \operatorname{Ser} 112$, which was proposed to function as the general base by deprotonating $\beta$ Tyr68, is protonated at $\mathrm{pH} 7.6$ with a $\mathrm{p} K_{\mathrm{a}}$ of $9.2 \underline{(26)}$. While no definitive role was proposed for $\beta$ Trp72, the X-ray crystal structure of PtNHase indicated that $\beta$ Trp72 forms a hydrogen bond with $\beta$ Tyr68 with a distance of $3.05 \AA$. This hydrogen-bonding interaction was proposed to stabilize the charge associated with a deprotonated tyrosine residue. However, based on sequence alignment between PtNHase and CtNHase, the residue corresponding to $\beta$ Trp72 in PtNHase is a valine in CtNHase (Figure 2). Therefore, the catalytic mechanism of $\mathrm{CtNHase}$ was examined kinetically in order to determine if $C t$ NHase functions similarly to PtNHase and also to gain insight into the role of $\beta$ Trp72 in the hydration of nitriles by NHase enzymes.

The kinetic parameters $K_{\mathrm{m}}, k_{\mathrm{cat}}$, and $k_{\mathrm{cat}} / K_{\mathrm{m}}$ for the hydration of acrylonitrile as a function of $\mathrm{pH}$ were examined, providing a bell-shaped curve for plots of relative activity vs $\mathrm{pH}$ over the $\mathrm{pH}$ values $4-10$. These data are nearly identical to those observed for PtNHase and the Co-type NHase from Pseudomonas putida NRRL-18668 $(26,41)$. Slopes of one were observed for $C t N H a s e$ as well as PtNHase (26), indicating that one ionizable group ( $\mathrm{p} K_{\mathrm{ES} 1}$ ) must be deprotonated while a second ionizable group $\left(\mathrm{p} K_{\mathrm{ES} 2}\right)$ must be in the protonated form in the ES complex for catalysis to occur in both Fe-type and Co-type NHase enzymes. Assignment of the observed $p K_{\mathrm{ES}}$ values is difficult, but as previously suggested for PtNHase (26), the most likely candidates for the observed deprotonation process ( $\mathrm{p} K_{\mathrm{ES} 1}$ ) are an active site residue such as $\beta$ Tyr68 or the metal-coordinated sulfinic acid 
(whose putative $\mathrm{p} K_{\mathrm{a}}$ in NHase is $7.6(40)$ ). Based on the temperature dependence of the ionization constant, the most likely assignment for the observed $\mathrm{p} K_{\mathrm{ES} 1}$ in CtNHase is $\beta$ Tyr68, similar to PtNHase (26). The assignment of $\mathrm{p} K_{\mathrm{ES} 1}$ to $\beta$ Tyr68 suggests that this residue can function to shuttle protons, consistent with the observed 17-fold decrease in $k_{\text {cat }}$ for the $\beta$ Tyr68Phe-mutated PtNHase enzyme (1). The fact that $K_{\mathrm{m}}$ also increases more than $10-$ fold for this mutant also suggests that $\beta$ Tyr 68 plays a role in binding and positioning the substrate, which in turn suggests the $\beta$ Tyr68 may help to stabilize the transition state. This $\mathrm{p} K_{\mathrm{ES} 1}$ value is not the metal-bound water molecule, since ENDOR data recorded in both ${ }^{1} \mathrm{H}_{2} \mathrm{O}$ and ${ }^{2} \mathrm{H}_{2} \mathrm{O}$ as well as in ${ }^{17} \mathrm{O}$-labeled water on the Fe-type NHase from Brevibacterium sp. strain R312 indicated that a water molecule, not an hydroxide, is bound to the metal center at $\mathrm{pH} 7.5$ (41). The most likely assignment for $\mathrm{p} K_{\mathrm{ES} 2}$ is the deprotonation of $\alpha$ Ser116, as proposed for PtNHase (26). Alternatively, $\mathrm{p} K_{\mathrm{ES} 2}$ may be due to the deprotonation of conserved active site arginine residues that have been shown to form hydrogen bonds with the sulfenic/sulfinic acid ligands of the active site $(1,20-22)$. Based on the temperature dependence of the ionization constant, the best assignment for $\mathrm{p} K_{\mathrm{ES} 2}$ is $\alpha \operatorname{Ser} 116$. Similar to $\mathrm{p} K_{\mathrm{ES} 1}, \mathrm{p} K_{\mathrm{E} 1}$ is most likely due to $\beta$ Tyr68 but could also be due to the deprotonation of a metalcoordinated sulfinic acid (40). Since the $\mathrm{p} K_{\mathrm{E} 2}$ value is similar to the $\mathrm{p} K_{\mathrm{ES} 2}$ value, it is most likely $\alpha$ Ser116 but may also be due to active site arginine residues.

Kinetic isotope effect studies provide a simple way to gain insight into the nature of the rate-limiting step and also provide information on the nature of the transition state (42). Primary isotope effects are observed if a bond to the labeled atom is made or broken during the reaction, whereas secondary isotope effects describe processes at other positions. Therefore, the solvent isotope effect of $\mathrm{CtNHase}$ using acrylonitrile as the substrate at $\mathrm{pH} 7.2$ was examined by substituting hydrogen $\left({ }^{1} \mathrm{H}\right)$ with deuterium $\left({ }^{2} \mathrm{H}\right)$. The presence of $\mathrm{D}_{2} \mathrm{O}$ lowers the catalytic activity of $\mathrm{CtNHase}$, resulting in a solvent isotope effect of 2.55. This solvent isotope effect is in good agreement with the value (2.07) reported for PtNHase (26). The normal isotope effect observed for both CtNHase and PtNHase suggests that for both Fe-type and Co-type NHases, an O-H bond is broken in the ratelimiting step.

Analysis of the midpoint solvent isotope effect for $\mathrm{CtNHase}$ also supports the involvement of two protons in the catalytic reaction. For $C t N H a s e, V_{n} / V_{0}$ deviates from linearity, and the best fit indicates two protons are transferred during catalysis with similar fractionation factors ( 0.62 and 0.63 ). These data also compare well with those reported for PtNHase, since the plot of $V_{n} / V_{0}$ for PtNHase also deviates from linearity, indicating two protons are transferred with fractionation factors of 0.66 and 0.68 (26). Therefore, Fe-type and Co-type NHase enzymes both transfer two protons in the transition state of their catalytic reactions. As proposed for PtNHase (26), these data are consistent with the transfer of a proton from an active site water molecule to an active site base forming a more nucleophilic hydroxide and the transfer of a proton from the hydroxyl group of the imine intermediate to form the amide. Conversely, it may also represent the transfer of a proton from the hydroxyl group of the imine intermediate to an active site base and the transfer of a proton from an active site base to the imine to form the amide. The first fractionation factor $\left(\varphi_{\mathrm{T} 1}=0.62\right)$ is characteristic of a proton-oxygen bond (neutral oxygen, $0.8-1.2$ ) with a conventional isotope effect equal to one (35). Since $\beta$ Tyr68 is deprotonated at $\mathrm{pH} 7.2$ (its $\mathrm{p} K_{\mathrm{a}}$ in the enzyme substrate complex is 6.1 ), a proton is likely shuttled between $\beta$ Tyr68 and $\alpha \operatorname{Ser} 116$, which eventually donates that proton to the substrate forming the amine.

The activation energy $\left(E_{\mathrm{a}}\right)$ for the activated $\mathrm{ES}^{\ddagger}$ complex was found to be $33.3 \mathrm{~kJ} / \mathrm{mol}$ for $C t$ NHase, which is nearly identical to the value previously reported for the Fe-type NHase from Brevibacterium imperialis CBS 489$74(38.4 \mathrm{~kJ} / \mathrm{mol})$ (43). However, the $E_{\mathrm{a}}$ value determined for $C t$ NHase is $\sim 30 \%$ higher than the $E_{\mathrm{a}}$ value determined for PtNHase (26). These data are consistent with the suggestion that transition state formation is more viable for Co-type than Fe-type NHase enzymes (43). The enthalpy of activation was calculated to be 30.8 $\mathrm{kJ} / \mathrm{mol}$ while the entropy of activation was found to be $-110.0 \mathrm{~J} / \mathrm{mol}$ for $\mathrm{CtNHase}$, at $20^{\circ} \mathrm{C}$, values similar to those found for PtNHase (26). The positive enthalpy is indicative of a conformation change upon substrate binding, likely due to the energy of bond formation and breaking during nucleophilic attack on the scissile carbon of the substrate. On the other hand, the negative entropy value suggests that some molecular motions 
are lost upon $\mathrm{ES}^{\ddagger}$ complex formation, likely due to hydrogen bond formation between catalytically relevant active site residues and active site water molecules and/or the substrate. This is consistent with the proton inventory data obtained at $\mathrm{pH} 7.2$, where multiple proton exchanges take place. All of these factors contribute to the positive free energy of activation. Since the observed $K_{\mathrm{m}}$ value also increases with temperature, thermodynamic parameters for the formation of the Michaelis complex at $25^{\circ} \mathrm{C}$ were also determined. The observed negative $\Delta G^{\circ}$ value indicates that the formation of the ES complex is thermodynamically favorable and the reaction catalyzed by $C t N H a s e$ is slightly exothermic. However, $\Delta S^{\circ}$ was found to be negative, suggesting the ES complex is highly ordered possibly due to an extensive hydrogen bond network consistent with the observed solvent isotope effect. These data are also consistent with those obtained for PtNHase (26).

In summary, the data presented herein strongly indicate that Fe-type NHase enzymes catalyze the hydration of nitriles via the same catalytic mechanism as Co-type enzymes (Figure ㄱ). Given the strong similarities in the kinetic data obtained for both Co-type and Fe-type NHase enzymes, $\beta \operatorname{Trp} 72$ in PtNHase, which is absent in CtNHase, is not required for catalysis to occur. However, when another amino acid, such as $\beta$ Trp72, that is capable of forming a hydrogen bond is present, it may assist in stabilizing the negative charge on $\beta$ Tyr68. As proposed for PtNHase (26), $\beta$ Tyr68 in CtNHase is deprotonated at $\mathrm{pH} 7.2$ with a corresponding $\mathrm{p} K_{\mathrm{a}}$ of 6.1. The strictly conserved residue $\alpha$ Ser116 likely functions to deprotonate $\beta$ Tyr68, functioning as the active site general base. Displacement of the metal-bound water molecule by a nitrile activated the $\mathrm{CN}$ bond toward nucleophilic attack placing the water molecule in the proper orientation, with regard to $\beta$ Tyr68 and $\alpha$ Ser 116 , for the addition of an $\mathrm{OH}$ bond across the nitrile $\mathrm{CN}$ bond. Given that two protons are transferred in the transition state for both Fe- and Co-type NHase enzymes, we propose that the one proton transfer occurs between an active site water molecule and the nitrile $\mathrm{N}$ atom while the second transfer occurs between an active site water molecule and $\beta$ Try68, consistent with the observed normal isotope effect, as previously proposed (26). Once proton transfer occurs, the resulting imidate can tautomerize to form an amide with a subsequent proton transfer from $\alpha$ Ser116, which functions to shuttle protons from $\beta$ Tyr68. Finally, the amide product can be displaced by a water molecule providing the regenerated catalyst. Therefore, both Fe-type and Co-type NHase enzymes likely catalyze the hydration of nitriles utilizing the same catalytic mechanism.

Figure 7

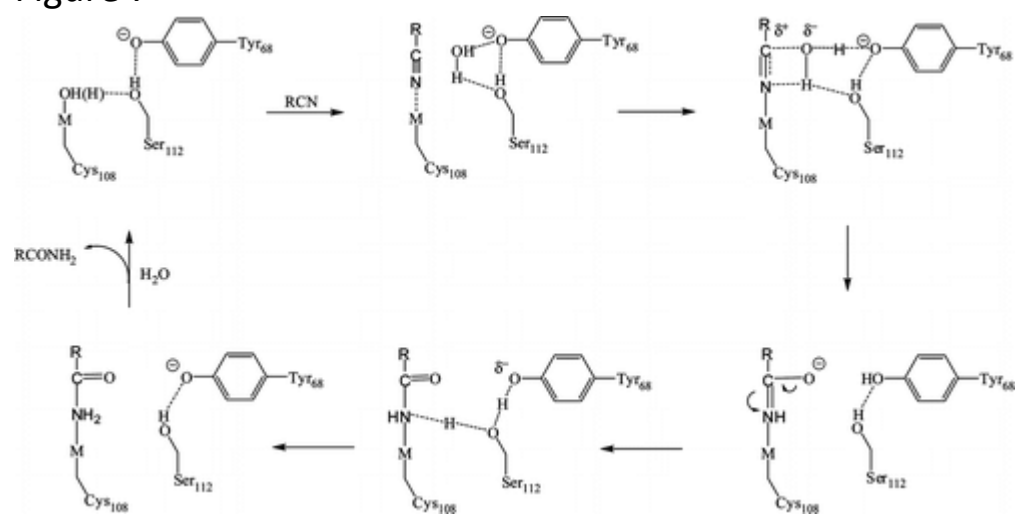

Figure 7. Proposed catalytic mechanism for NHase enzymes.

\section{Abbreviations}

CtNHase, Fe-type NHase from Comamonas testosteroni Ni1; PtNHase, Co-type NHase from Pseudonocardia thermophila JCM 3095; HEPES, 4-(2-hydroxyethyl)-1-piperazineethanesulfonic acid; LB, Luria-Bertani medium.

\section{References}

$\underline{1}$ Miyanaga, A., Fushinobu, S., Ito, K., Shoun, H., and Wakagi, T. (2004) Mutational and structural analysis of cobalt-containing nitrile hydratase on substrate and metal binding Eur. J. Biochem. 271, 429-438 
$\underline{2}$ Elrod, J. P., Hogg, J. L., Quinn, D. M., Venkatasubban, K. S., and Schowen, R. L. (1980) Protionic reorganization and substrate structure in catalysis by serine proteases J. Am. Chem. Soc. 102, 3917-3922

$\underline{\mathbf{3}}$ Petrillo, K. L., Wu, S., Hann, E. C., Cooling, F. B., Ben-Bassat, A., Gavagan, J. E., Dicosimo, R., and Payne, M. S. (2005) Over-expression in Escherichia coli of a thermally stable and regio-selective nitrile hydratase from Comamonas testosteroni 5-MGAM-4D Appl. Microbiol. Biotechnol. (in press)

4 Padmakumar, R. and Oriel, P. (1999) Bioconversion of acrylonitrile to acrylamide using a thermostable nitrile hydratase Appl. Biochem. Biotechnol. 77-79, 671-679

$\underline{5}$ Nagasawa, T. and Yamada, H. (1995) Microbial production of commodity chemicals Pure Appl. Chem. 67, 1241- 1256

6 Mylerova, V. and Martinkova, L. (2003) Synthetic applications of nitrile-converting enzymes Curr. Org. Chem. 7, $1-17$

$\underline{7}$ Kovacs, J. A. (2004) Synthetic analogues of cysteinate-ligated non-heme iron and non-corrinoid cobalt enzymes Chem. Rev. 104, 825-848

$\underline{8}$ Banerjee, A., Sharma, R., and Banerjee, U. C. (2002) The nitrile-degrading enzymes: current status and future prospects Appl. Microbiol. Biotechnol. 60, 33-44

$\underline{9}$ Hjort, C. M., Godfredsen, S. E., and Emborg, C. (1990) Isolation and characterization of a nitrile hydratase from a Rhodococcus sp J. Chem. Technol. Biotechnol. 48, 217-226

10 Nagasawa, T., Shimizu, H., and Yamada, H. (1993) The superiority of the third-generation catalyst, Rhodococcus rhodochrous J1 nitrile hydratase, for industrial production of acrylamide Appl. Microbiol. Biotechnol. 40

11 Nagashima, S., Nakasako, M., Dohmae, N., Tsujimura, M., Takio, K., Odaka, M., Yohda, M., Kamiya, N., and Endo, I. (1998) Novel non-heme iron center of nitrile hydratase with a claw setting of oxygen atoms Nat. Struct. Biol. 5, 347- 351

$\underline{12}$ Endo, I., Nojiri, M., Tsujimura, M., Nakasako, M., Nagashima, S., Yohda, M., and Odaka, M. (2001) Fe-type nitrile hydratase J. Inorg. Biochem. 83, 247-253

13 Shaw, N. M., Robins, K. T., and Kiener, A. (2003) Lonza: 20 years of biotransformations Adv. Synth. Catal. 345, 425- 435

14 Wu, Z. L. and Li, Z. Y. (2003) Highly enantioselective synthesis of alpha, alpha-disubstituted malonamic acids through asymmetric hydrolysis of dinitriles with Rhodococcus sp. CGMCC 0497 Chem. Commun. 3, 386387

15 Dadd, M. R., Claridge, T. D., Walton, R., Pettman, A. J., and Knowles, C. J. (2001) Regioselective biotransformation of the dinitrile compounds 2-, 3- and 4-(cyanomethyl) benzonitrile by the soil bacterium Rhodococcus rhodochrous LL100-21 Enzyme Microb. Technol. 29, 20-27

16 Martnkov, L., Klempier, N., Prepechalov, I., Prikrylov, V., Ovesn, M., Griengl, H., and Kren, V. (1998) Chemoselective biotransformation of nitriles by Rhodococcus equi A4 Biotechnol. Lett. 20, 909-912

17 Cowan, D. A., Cramp, R. A., Pereira, R., Graham, D., and Almatawah, Q. (1998) Biochemistry and biotechnology of mesophilic and thermophilic nitrile metabolizing enzymes Extremophiles 2, 207- 216

18 Tauber, M. M., Cavaco-Paulo, A., Robra, K.-H., and Gübitz, G. M. (2000) Nitrile hydratase and amidase from Rhodococcus rhodochrous hydrolyze acrylic fibers and granular polyacrylonitriles Appl. Environ. Microbiol. 66, 1634- 1638

19 Harrop, T. C. and Mascharak, P. K. (2004) Fe(III) and Co(III) centers with carboxamido nitrogen and modified sulfur coordination: lessons learned from nitrile hydratase Acc. Chem. Res. 37, 253- 260

$\underline{20}$ Hourai, S., Miki, M., Takashima, Y., Mitsuda, S., and Yanagi, K. (2003) Crystal structure of nitrile hydratase from a thermophilic Bacillus smithii Biochem. Biophys. Res. Commun. 312, 340- 345

21 Huang, W., Jia, J., Cummings, J., Nelson, M., Schneider, G., and Lindqvist, Y. (1997) Crystal structure of nitrile hydratase reveals a novel iron centre in a novel fold Structure 15, 691-699

22 Miyanaga, A., Fushinobu, S., Ito, K., and Wakagi, T. (2001) Crystal structure of cobalt-containing nitrile hydratase Biochem. Biophys. Res. Commun. 288, 1169- 1174

23 Song, L., Wang, M., Shi, J., Xue, Z., Wang, M. X., and Qian, S. (2007) High resolution X-ray molecular structure of the nitrile hydratase from Rhodococcus erythropolis AJ270 reveals posttranslational oxidation of two 
cysteines into sulfinic acids and a novel biocatalytic mechanism Biochem. Biophys. Res. Commun. 362, 319- 324

24 Boone, A. J., Cory, M. G., Scott, M. J., Zerner, M. C., and Richards, N. G. (2001) Investigating the structural and electronic properties of nitrile hydratase model iron(III) complexes using projected unrestricted HartreeFock (PUHF) calculations Inorg. Chem. 40, 1837- 1845

25 Mascharak, P. K. (2002) Structural and functional models of nitrile hydratase Coord. Chem. Rev. 225, 201214

26 Mitra, S. and Holz, R. C. (2007) Unraveling the catalytic mechanism of nitrile hydratases J. Biol. Chem. 282, 7397- 7404

27 Stevens, J. M., Rao Saroja, N., Jaouen, M., Belghazi, M., Schmitter, J.-M., Mansuy, D., Artaud, I., and Sari, M.A. (2003) Chaperone-assisted expression, purification, and characterization of recombinant nitrile hydratase NI1 from Comamonas testosteroni Protein Expression Purif. 29, 70- 76

$\underline{28}$ Bradford, M. M. (1976) A rapid and sensitive method for quantitation of microgram quantities of protein utilizing the principle of protein-dye binding Anal. Biochem. 72, 248- 254

29 Salomaa, P., Schaleger, L. L., and Long, F. A. (1964) Solvent deuterium isotope effects on acid-base equilibria J. Am. Chem. Soc. 86, 1-7

30 Okamoto, S. and Eltis, L. D. (2007) Purification and characterization of a novel nitrile hydratase from Rhodococcus sp. RHA1 Mol. Microbiol. 65, 828- 838

31 Pereira, R. A., Graham, D., Rainey, F., and Cowan, D. A. (1998) A novel thermostable nitrile hydratase Extremophiles 2, 347- 357

$\underline{32}$ Segel, I. H. (1993) Enzyme Kinetics. Behavior and Analysis of Rapid Equilibrium and Steady-State Enzyme Systems, John Wiley \& Sons, New York.

$\underline{33}$ Cleland, W. W. (1977) Adv. Enzymol. Relat. Areas Mol. Biol. 45, 273- 387

34 Albery, W. J. (1975) Proton Transfer Reactions, Chapman and Hall, London.

$\underline{35}$ Venkatasubban, K. S. and Schowen, R. L. (1984) The proton inventory technique CRC Crit. Rev. Biochem. 17, $1-44$

36 Bzymek, K. P. and Holz, R. C. (2004) The catalytic role of glutamate-151 in the leucine aminopeptidase from Aeromonas proteolytica J. Biol. Chem. 279, 31018- 31025

37 Izatt, R. M. and Christensen, J. J. (1976) Heats of proton ionization, pK, and related thermodynamic quantities, Vol. 1, 3rd ed., CRC Press, Cleveland, $\mathrm{OH}$.

38 Chen, G., Edwards, T., D'souza, V. M., and Holz, R. C. (1997) Mechanistic studies on the aminopeptidase from Aeromonas proteolytica: A two-metal ion mechanism for peptide hydrolysis Biochemistry 36, 42784286

39 Bienvenue, D. L., Mathew, R. S., Ringe, D., and Holz, R. C. (2002) The aminopeptidase from Aeromonas proteolytica can function as an esterase J. Biol. Inorg. Chem. 7, 129- 135

40 Dey, A., Chow, M., Taniguchi, K., Lugo-Mas, P., Davin, S., Maeda, M., Kovacs, J. A., Odaka, M., Hodgson, K. O., Hedman, B., and Solomon, E. I. (2006) Sulfur K-edge XAS and DFT calculations on nitrile hydratase: geometric and electronic structure of the non-heme iron active site J. Am. Chem. Soc. 128, 533-541

$\underline{41}$ Jin, H., Turner, J. I. M., Nelson, M. J., Gurbiel, R. J., Doan, P. E., and Hoffman, B. M. (1993) Coordination sphere of the ferric ion in nitrile hydratase J. Am. Chem. Soc. 115, 5290- 5291

$\underline{42}$ Cleland, W. W. (1982) Use of isotope effects to elucidate enzyme mechanisms Crit. Rev. Biochem. 13, 385427

43 Alfani, F., Cantarella, M., Spera, A., and Viparelli, P. (2001) Operational stability of Brevibacterium imperialis CBS 489-74 nitrile hydratase J. Mol. Catal. B 11, 687- 697 